quartiles being 30 and 39 and the extremes 27 and 44).

In golf, the thirty-seven open champions since 1894 show a median age of 31 years (the quartiles being 28 and 37 and the extremes 23 and 44 ).

\section{THEORETICAL IMPLICATIONS}

A most important development in modern psychology is the search for innate, basic, unitary traits of personality. There is accumulative evidence in favour of the existence of a number of unitary traits or factors, and it has been found convenient to denote them provisionally by letters of the alphabet, analogous to a practice of physics and other sciences. This does not in the least imply that their functional interpretation is necessarily less clear than that of concepts such as introversion and the like. It is true that poly. syllabic words have sometimes only to undergo a very cursory censorship, but this practice leads to abuses of the language mechanism which may retard individual cerebral evolution. Besides, the less popular use of letters to denote new concepts is not likely to proceed indefinitely, if only for the fact that the introduction of such a letter is preceded by many thousand hours of laborious work.

Closely connected with the study of traits is the difficult question of the effectiveness of past experiences. Spearman's researches show that retentivity is independent of $g$, and there is evidence that the old tend to deteriorate in tests of immediate memory. How far is the balance redressed when the extent and variety of all their previous experiences as well as their integration is taken into account? It is scarcely necessary to illustrate the dire effects of lack of experience. Thus the brilliant young debater is often pulverised by one who is dull but elderly. My second example is a very intelligent person who has been totally blind from birth. I found that the subject had no idea at all of the size of the sun as it appeared in the sky. The subject imagined that most stars had five points, but that some had six or even eight, and that a rainbow had the shape of a tied bow, and so forth. Manifestly all knowing, even in the case of the gifted, must start from experiencing.

Now that the method of factorial analysis is becoming increasingly effective, not only in the case of cognitive abilities, but also with regard to personality in all its aspects, it becomes necessary to study age as one of the 'primordial potencies' more systematically, not only during childhood and adolescence, but also throughout the life-span. This will determine the relative importance of the various traits at different stages of life, and in turn will lead to a fuller psychological interpretation of the unitary traits themselves.

\title{
Recent Advances in Seismology*
}

\section{By Dr. F. J. W. Whipple, Kew Observatory, Richmond, Surrey}

SEISMOLOGY, the science of earthquakes, is $S$ primarily concerned with such questions as where, how and why earthquakes occur, but it is also concerned with the question how the waves generated by earthquakes travel through the earth, and with the question what information as to the constitution of the earth can be deduced from the behaviour of the waves. Living in a country which is seldom troubled by earthquakes, but a country in which the waves from distant earthquakes can be studied, we have a more direct interest in questions of the latter types. This interest has been fostered by the British Association, which has facilitated the discussion and collection of the records from observatories in all parts of the world. This is an enterprise of which we may well be proud.

* Paper read before Section A of the British Association at Norwich on September 9 , opening a discussion on recent advances in seismology.
John Milne, who was a great pioneer, organised the collection of observations. He used to publish lists of the readings of the seismograms at as many observatories as possible. On the death of Milne, Prof. H. H. Turner, who was already chairman of the B.A. committee, accepted responsibility for the work, which he transferred to the University Observatory, Oxford, and soon began the publication of the observations in a more convenient form, dealing with each earthquake separately. This arrangement was continued when Turner became president of the Seismological Section of the International Union for Geodesy and Geophysics. The collections of observations are now known as the International Seismological Summary. As the number and efficiency of seismological stations has increased, so the I.S.S. has grown. The Summary for 1930 is a substantial volume of 426 pages. Since Turner's death in 
1930 , the work has been carried on most loyally and efficiently by Mr. Hughes and Miss Bellamy. Seismologists are under a great debt of gratitude to them, and to Prof. H. H. Plaskett who has given facilities for the continuation of the work.

The I.S.S. provides a wealth of material for research. One of the objects which Turner had at heart was the preparation of more reliable tables of the travel times of earthquakes. This task was eventually undertaken by Dr. H. Jeffreys, whose revised tables for the times of $P$ and $S$ waves were published in 1932. Jeffreys regarded this work as a preliminary to a closer examination of the material, and with the help of Mr. K. E. Bullen he discussed the records of 61 earthquakes. For each the epicentre was redetermined and a close examination of the material of the I.S.S. was made to discover the reflected waves of different types.

The results of this heavy investigation were presented by Jeffreys at the Lisbon meeting of the I.S.A. two years ago, and have now been published. It was not to be expected that there would be anything very exciting in the results. Perhaps that is the strongest reason for admiring the enterprise of Jeffreys and Bullen. The most striking development is the confirmation of an irregularity in the run of the times of transmission of the waves of compression and distortion. This irregularity, which occurs at ranges of about $20^{\circ}$, had previously been studied by Miss Lehmann of Copenhagen and probably signifies that there is a discontinuity in the nature of the rocks at a depth of about $400 \mathrm{~km}$.

An interesting development was the calculation by an indirect method of the time required for shearing waves to travel to the core and back. An $S$ wave which reaches the core is resolved into a reflected wave, known as $S c S$, and a transmitted $K$ wave. When a $K$ wave reaches the boundary of the core again, some of the energy passes out as an $S$ wave and some is reflected to pass out further on. Thus $S K S$ and $S K K S$ are produced. It is clear that the time of transmission of the $S K S$ is the mean between the times for the $S c S$ and $S K K S$ waves. Thus the time for $S C S$ waves where they are not readily observed could be calculated. It should be mentioned that Dr. Jeffreys has recently revised this $S c S$ table, using records for deep focus earthquakes.

The Jeffreys and Bullen tables are now being used as the standard of reference of the I.S.S. so that they will be the starting point for the investigations of such questions as the possible departure of the earth from spherical symmetry.

The most spectacular of recent advances in seismology is in our knowledge of earthquakes with deep foci. Turner was led to the discovery of such earthquakes by finding that the ordinary tables of transmission times, which were reasonably satisfactory for ordinary earthquakes, were not applicable in certain cases. He was led to attribute the abnormality to the depth of foci, which might in some cases be so great as 9 per cent of the earth's radius, or $500 \mathrm{~km}$. Similar conclusions were reached by Wadati in Japan, and the theory was confirmed by the close analysis of world-wide records by Scrase and Stechschulte.

That the great majority of the earthquakes were to be found round the Pacific was noticed by

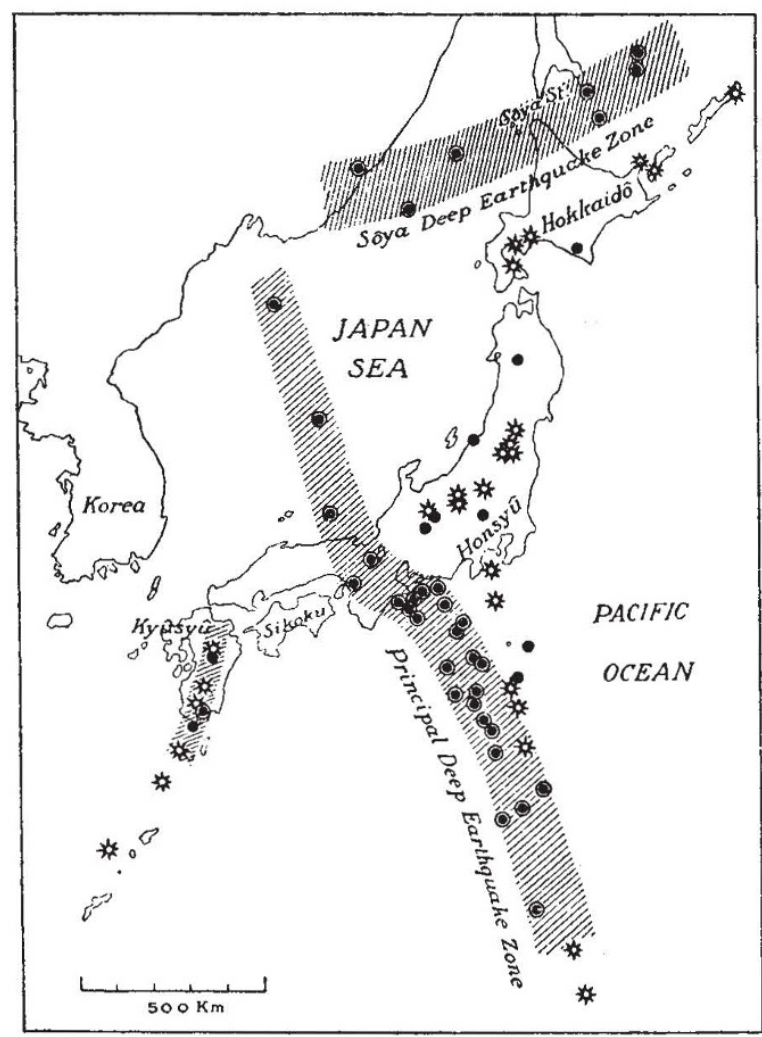

FIG. 1. Deep-focus earthquake zones and volcanoes.

Deep earthquakes which occurred during 1927-33; * Volcanoes which have been in eruption since 1867 . From Geophysical Magazine (Tokyo), 8, No. $2 ; 1934$.

Turner. Japanese seismologists have mapped the foci near their own country with striking results. There is a remarkably orderly arrangement. Not only are the foci to be found on two belts meeting at right angles on the continental side of the sea of Japan, but also the depths are systematically arranged, the greatest on the outside of the angle formed by the belts.

In Fig. 1, which is due to H. Honda, the positions of the zones in which deep-focus earthquakes occur are shown, together with the positions of such volcanoes as have been in eruption since 1867. Fig. 2 is reproduced from a paper by $\mathrm{K}$. Wadati. In this diagram the two principal zones 
of deep focus earthquakes are joined by lines which serve to emphasise the distribution of

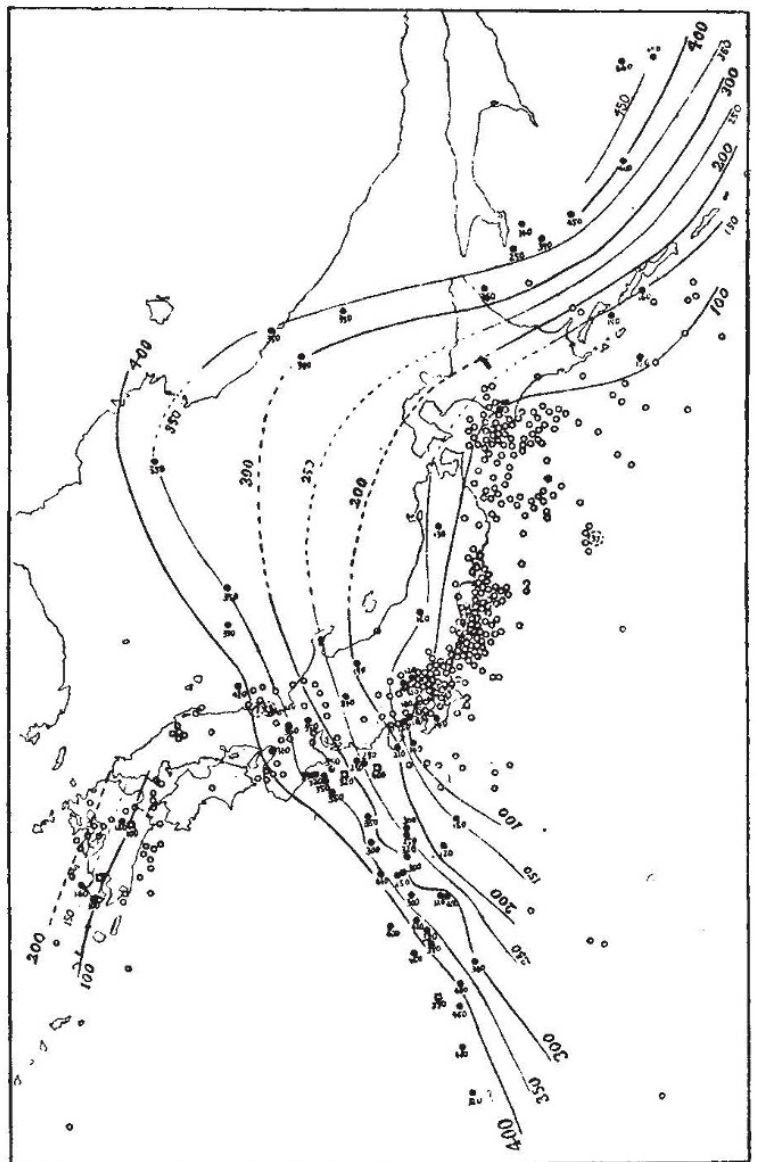

Fig. 2. Lines of equal focal depth for deep-focus earthquakes. Deep-focus earthquakes; $O$ shallow-focus earthquakes; $\square$, foci not accurately determined. From Geophysical Magazine (Tokyo), 8, Nos.

depth. The innermost of these lines indicates the position of foci with depths of $100 \mathrm{~km}$., the outer- most of the main series of lines indicates a depth of $400 \mathrm{~km}$. The way in which the foci of ordinary earthquakes cluster on the east of Japan is also illustrated in this diagram.

The directions of the impulsive movements in deep-focus earthquakes with their foci near to the region where the main belt crosses Japan have been studied by Honda. He finds that at places to the north-east of the belt the ground moves downwards and towards the belt. At places to the south-west the movement is upwards and away from the belt. Thus it appears likely that huge faults extending to a depth of about $400 \mathrm{~km}$. or more can exist in the earth's crust and that deep foci are on such faults. Volcanoes, live and extinct, are found above the line where the fault is at a depth of $100 \mathrm{~km}$., whilst ordinary earthquakes with shallow focus occur near where the fault approaches the surface.

It has been suggested that the high frequency of earthquakes round the Pacific is due to the fact that the crust of the earth below an ocean cools more rapidly than the crust over the continents, where the radioactivity of the granite provides a source of heat.

In various studies of the times of transmission of seismic waves it has been found that the thickness of the continental granite is about $15 \mathrm{~km}$. Thus the occurrence of deep-focus earthquakes implies that the strains in the crust lead to fractures at depths of the order twenty times the probable thickness of the granite. Can it be that the influence of a mere skin extends to such a depth? These foci are also far below the level at which isostatic compensation has been supposed hitherto to be operative. It is clear that they must be taken into account in all speculations as to the history of the globe.

\section{Obituary}

Prof. Henry Fairfield Osborn, For.Mem.R.S.

DROF. HENRY FAIRFIELD OSBORN, who died at his home, Castle Rock, Garrison-onHudson, N.Y., on November 6, 1935, was one of the foremost palæontologists of the United States, and made great contributions to our knowledge of fossil mammals and reptiles. He was born on August 8, 1857, at Fairfield, Connecticut, and began his scientific education in 1873 at Princeton College (afterwards University), where he was influenced especially by President James McCosh, the psychologist, and Prof. Arnold Guyot, the geologist. After graduating in 1877, he studied human anatomy and histology under Prof. William H. Welch, in New York; and in 1879-80 he followed brief courses in embryology under F. M. Balfour at Cambridge, and in comparative anatomy under Huxley in London. $\mathrm{He}$ then returned to Princeton with a biological fellowship, and in 1881 he was appointed assistant professor of natural science. In 1883 he was promoted to the professorship of comparative anatomy at Princeton, where he remained until 1891.

While Osborn was a student at Princeton, great interest was being aroused by the discoveries of numerous strange extinct mammals and reptiles by Cope and Marsh in the rocks of the western United States. At the end of his course, therefore, in 1877, he and his fellow-students, W. B. Scott and F. Speir, decided to undertake a summer trip to Wyoming in search of similar fossils, and they brought back a 